\title{
Science Smiles
}

Ayan Guha

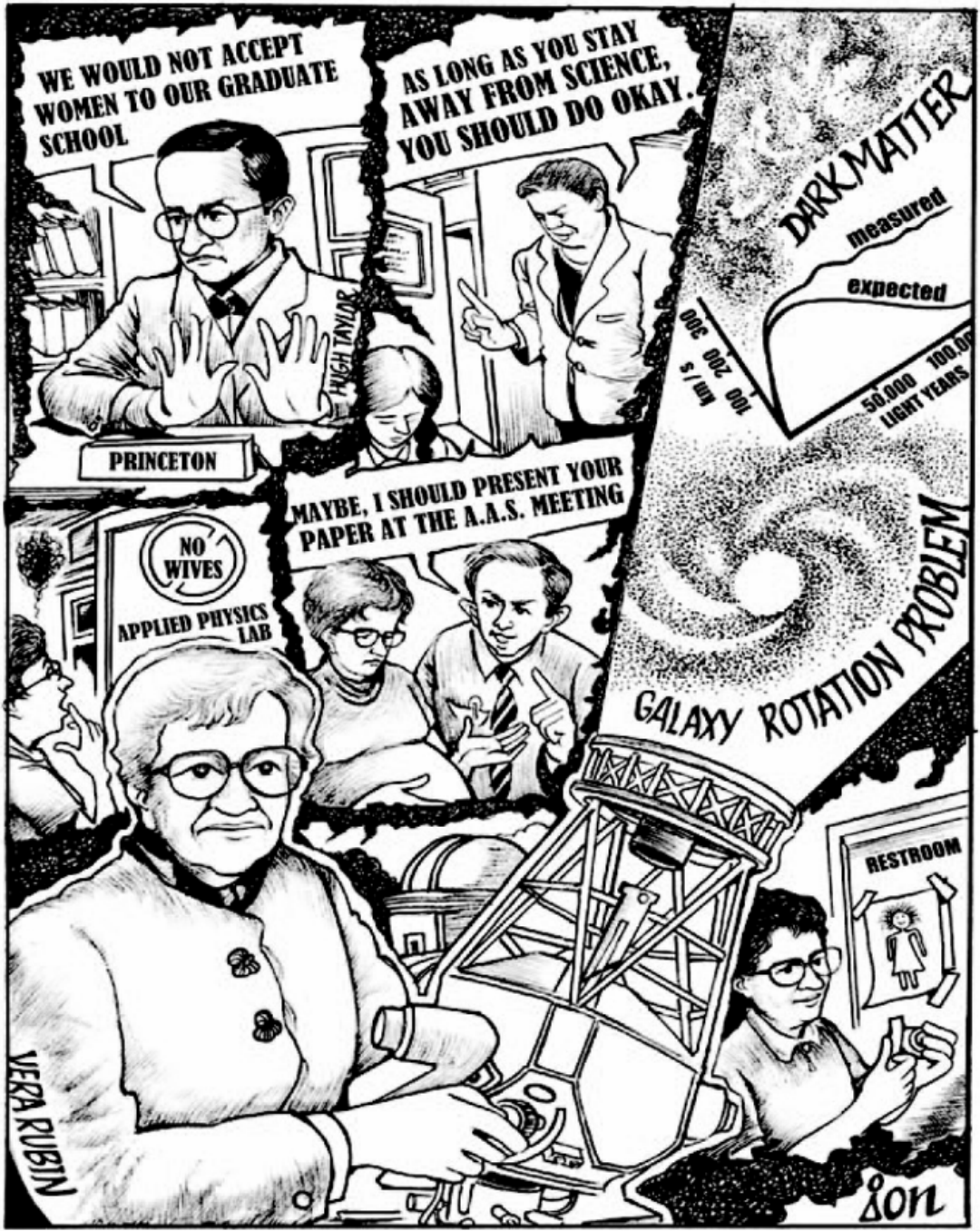

"Don't let anyone keep you down for silly reasons such as who you are. And don't worry about prizes and fame. The real prize is finding something new." (Vera Cooper Rubin) 